\title{
Impact of a pharmacist-driven pharmacovigilance system in a secondary hospital in the Gauteng Province of South Africa
}

Antionette Terblanche ${ }^{1,2}$, BPharm, MPharm; Johanna Catharina Meyer ${ }^{1}$, BPharm, MSc (Med), PhD (Pharmacy); Brian Godman ${ }^{1,3,4,5}$, BSc, PhD; Robert Stanley Summers ${ }^{1}$, BPharm, MSc (Med), PhD (Pharmacy).

1Department of Public Health Pharmacy and Management, School of Pharmacy, Sefako Makgatho Health Sciences University, Ga-Rankuwa, Pretoria, South Africa. Email: Antionette.Terblanche@gauteng.gov.za; hannelie.meyer@smu.ac.za, ORCID number: 0000-00030462-5713; robert.summers@smu.ac.za

2Department of Pharmacy, Sebokeng Hospital Pharmacy, Sebokeng Hospital, Gauteng, South Africa. Email: antionette.terblanche@gauteng.gov.za

${ }^{3}$ Division of Clinical Pharmacology, Karolinska Institute, Stockholm, Sweden. Email:

Brian.Godman@ki.se ORCID number: 0000-0001-6539-6972

${ }^{4}$ Strathclyde Institute of Pharmacy and Biomedical Sciences, University of Strathclyde, Glasgow, UK. Email: Brian.Godman@strath.ac.uk

${ }^{5}$ Health Economics Centre, Liverpool University Management School, Chatham Street, Liverpool, UK. Email: Brian.Godman@liverpool.ac.uk

*Author for correspondence. Division of Clinical Pharmacology, Karolinska Institute, Karolinska University Hospital Huddinge, SE-141 86, Stockholm, Sweden. Email: Brian.Godman@ki.se. Telephone + 46858581068 . Fax + 46859581070 and Strathclyde Institute of Pharmacy and Biomedical Sciences, University of Strathclyde, Glasgow G4 ORE, United Kingdom. Email: brian.godman@strath.ac.uk. Telephone: 0141548 3825. Fax: 01415522562

(Accepted for publication in Hospital Practice Journal - Please keep CONFIDENTIAL)

Keywords: intervention, patient safety, adverse drug reaction reporting, pharmacovigilance, Pharmacists, medicine management

\section{ABSTRACT}

Background and aims: Under-reporting of adverse drug reactions (ADRs) by health care professionals (HCPs) is a worldwide problem. Spontaneous reporting in hospitals is scarce and several obstacles have been identified. Improved hospital-based reports could make important contributions to future care. Consequently, the objective of this study was to develop, implement and evaluate a structured pharmacist-driven pharmacovigilance (PV) system for in-patient ADR reporting in a leading public hospital in South Africa, for future use in South Africa and wider. Method: Descriptive, operational intervention study with a pre-post design. Pharmacist-driven interventions targeted at ADR reporting were implemented. Convenience sampling was used to recruit HCPs (medical practitioners, pharmacists, pharmacist assistants and nurses) to complete a selfadministered questionnaire. The principal outcome measures were the number of the ADRs reported for inpatients 18 months prior to and 18 months during the intervention period as well as an evaluation of the intervention programme in terms of continuous information and training. Results: Significant increase in the number of HCPs reporting an ADR post-intervention (33.8\% up from $12.1 \%$; $p<0.0001)$. Reasons for non-reporting decreased significantly, e.g. 'How, where and when to report' an ADR ( $p=0.0027)$ and 'Concern that the report may be wrong' $(p=0.0041)$. HCPs knowledge of the ADR reporting system also improved appreciably apart from pharmacists who were already knowledgeable. Conclusion: The results showed the benefits of pharmacist-driven interventions on HCPs' knowledge and awareness of PV and the number of the ADRs reported. Hospital management and policy makers should consider the important role pharmacists can play in improving rational and safe use of medicines among inpatients, based on appropriate training of HCPs and proper systems. As a result, help achieve the standards established by the Department of Health in South Africa.

\section{Introduction}

Adverse drug reactions (ADRs) have the potential to cause significant harm to patients [1, 2], increasing morbidity and mortality, and adding to patient suffering [3-6]. As a result, there is growing awareness of the impact of ADRs on patient care and public health [7]. Overall, ADRs are among the leading causes of mortality across countries $[5,6,8,9]$, enhanced by an appreciable number of hospital admissions each year [10-16] as well as in-patient ADRs [17]. 
Within South Africa, an observational study conducted among medical wards of a secondary hospital in the Western Cape estimated that $6.3 \%$ of hospitalised patients were admitted as a direct result of an ADR, while a further $6.3 \%$ of patients developed a significant ADR while in hospital [18]. Another cross-sectional survey undertaken over a 30 day period in the medical wards of four hospitals in South Africa estimated that ADRs contributed to the death of $2.9 \%$ of medical admissions, and 56 of 357 deaths in the wards (16\%) were ADR-related [4].

As a result of the growing concerns with ADRs, the National Department of Health in South Africa in 2011 published its National Core Standards (NCS) to improve future quality of care. The reporting of ADRs formed part of the safety aspects of the NCS [19]. The National Health Act was subsequently amended on 24 July 2013 [20] to establish an independent public entity, the 'Office of Health Standards Compliance', as a new regulator to protect and promote health and safety in health services by monitoring and enforcing compliance within all health establishments using certain norms and standards. According to these standards, a clear pharmacovigilance (PV) system must be in place in each hospital to monitor and manage ADRs $[19,20]$.

To date within South Africa, there have been limited studies assessing the extent of ADR reporting and PV knowledge among health care professionals (HCPs) following the introduction of the NCS and the establishment of the Office of Health Standards Compliance. Prior to 2012, ADRs were also not formally reported in Sebokeng Hospital, one of the major secondary care referral public sector hospitals in the Gauteng Province, with 800 beds [21]. According to hospital statistics, no ADRs were reported between 2012 and November 2013 and only six ADRs were reported between December 2013 and May 2015 [22].

Pharmacists are typically in a unique situation to collect ADR data in hospitals, which when analysed and acted upon should improve the future use of medicines. We previously carried out a study to determine possible reasons for the lack of ADR reporting in public hospitals in South Africa [23] as the first step to implement and evaluate potential measures within the practice setting to improve both the quantity and quality of ADR reporting. Consequently, this study aimed to develop, implement and evaluate a structured pharmacist-driven PV system for ADR reporting at Sebokeng Hospital to address current concerns with low reporting rates. This manuscript reports on the outcomes of this operational process to provide future guidance

\section{Methodology}

\subsection{Study setting and design}

The study was conducted at Sebokeng Hospital, in the Sedibeng District of the Gauteng Province, South Africa [21]. This was a phased, operational, intervention study with a pre- and post-intervention comparison, to develop, implement, and evaluate a structured pharmacist-driven PV system for ADR reporting, conducted over a period of 20 months between 2015 and 2016. Figure 1 gives a schematic representation of the study design and process, which is described in more detail in Section 2.3.

\subsection{Study population}

The study population included all medical practitioners, pharmacists, pharmacists' assistants and nurses employed by Sebokeng hospital. At the time of the study, 547 medical practitioners, pharmacists, and nurses were employed by the hospital.

\subsection{Data collection, sample and intervention}

Phase A (pre-intervention) was an historic one month baseline and needs analysis conducted in May 2015, which has already been published [23]. Briefly, a retrospective review of records was conducted to determine the number of ADR reports submitted at Sebokeng Hospital for the 18-month period prior to the intervention, i.e. from November 2013 to April 2015 [23]. A needs analysis, using a self-administered questionnaire, was conducted amongst a convenient sample of $131 \mathrm{HCPs}$ regarding structures for, processes followed and outcomes of ADR reporting at the hospital [23].

Phase B (pharmacist-driven intervention) entailed the design and implementation of a pharmacistdriven PV system, implemented as an intervention by a pharmacist in all the wards to improve ADR reporting. The synopsis and findings of the baseline assessment and needs analysis conducted in Phase A guided the interventions in Phase B. Due to the operational nature of the project, the 
pharmacist continued with, and subsequently monitored the interventions (PV system) in practice, for a period of 18 months. This intervention period included various activities carried out by the pharmacist in the hospital, including continuous education and training on PV and ADR reporting, which took place at different forums in the hospital. Details on the various elements covered by the interventions are shown in Figure 1.

Phase C (post-intervention evaluation) was an evaluation of the structured PV system for ADR reporting and outcomes. Similar to Phase A, a retrospective review of the records was conducted to determine the number of ADR reports submitted during the intervention phase (Phase $B$ ). In addition, a conveniently selected sample of $151 \mathrm{HCPs}$, based on similar numbers to Phase A, completed the same self-administered questionnaire as in Phase A [23]. There were also additional questions specifically related to the interventions and the post-implementation to evaluate the acceptance and influence of the implemented PV system. Data collection took place in November 2016 and was similar to Phase A [23]. HCPs working in the hospital at the time of data collection were informed of the study using general communication to the wards.

As mentioned, convenience sampling was used to invite HCPs present in a particular ward at the time of data collection to participate in the study and complete the questionnaire. Written informed consent for participation was obtained. After this, HCPs were provided with the aims and objectives of the study and informed that their participation was voluntary. The questionnaire was subsequently completed in a private area in the ward or pharmacy and placed in a sealed container provided in the area. The differences in structures for the processes followed, as well as outcomes of ADR reporting prior to and after the implementation of the structured PV system, were determined based on the selfadministered questionnaire results. 
PHASE A: Pre-intervention baseline and needs analysis [23] (One month)
PHASE B: Implementation and continuation of pharmacist-driven interventions (PV system) (18 months)
PHASE C: Post-intervention evaluation (One month)
- Retrospective review of records: ADR reports submitted 18 months prior to the study

- Needs analysis with selfadministered questionnaire for HCPs

- Determine the number of ADRs reported (rate of ADR reporting)

18 months prior to the study

- Needs analysis with a selfadministered questionnaire for HCPs:

- Structures in place for ADR reporting

- Process followed

- Outcome of ADR reporting
- Develop and implement a pharmacist-driven structured PV system

- Continuation in practice of implemented pharmacist-driven structured PV system

Based on the findings of Phase $A$, the interventions implemented by the pharmacist included the following elements

- Provide information on the pharmacist-driven structured PV system at the relevant forums within the hospital continuously throughout the 18 months

- Provide interactive training for HCPs and support staff on ADRs, the reporting thereof and monitoring it

- Place posters in wards and other public areas to increase awareness of ADR reporting

- Introduce an applicable referral system and process for ADR reporting in the wards and monitoring it

- Increase accessibility of ADR forms and monitor completion thereof

- Place an example of a completed ADR form in each ward

- Create an ADR reporting 'WhatsApp' group for HCPs in the hospital

- Attendance of a pharmacist in the medical ward rounds and active involvement in education of healthcare workers

- Circulate and display SOPs for submission of completed ADR forms

- Submit completed ADR forms to Provincial and National PV offices and authorities

- Summarise and analyse reported ADRs for feedback to HCPs

- Monthly feedback on PV system at relevant forums within the hospital
- Retrospective review of records: ADR reports submitted during 18 months of Phase $B$

- Post-implementation selfadministered questionnaire for HCPs

- Determine the number of ADRs reported (rate of ADR reporting) during the 18 months of Phase $B$

- Post-implementation selfadministered questionnaire for HCPs:

- Structures in place for ADR reporting

- Process followed

- Outcome of ADR reporting

\section{EVALUATE THE STRUCTURED PHARMACIST-DRIVEN PV SYSTEM}

- Determine the difference in number of ADR reports submitted prior to and post the implementation of the structured PV system

- Determine the difference in structures for, process followed-and outcomes of ADR reporting prior to and post the implementation of the structured pharmacist-driven PV system

ADRs: Adverse drug reactions; HCPs: Health care professionals; PV: Pharmacovigilance; SOPs: Standard operating procedures

Figure 1. Study design and process 


\subsection{Data analysis}

Data were captured in Microsoft Excel ${ }^{\mathrm{TM}}$, proof-read for accuracy and cleaned for statistical analysis with SAS, release 9.2, running under Microsoft Windows. Characteristics of HCPs were summarised as frequencies and percentages.

The number of ADR reports submitted by the hospital over the 18-month period during the intervention phase (Phase $B$ ) of the study was determined and compared with the number submitted during the 18-month period prior to the implementation of the pharmacist-driven PV system (Phase A). Proportions of HCPs with knowledge and attitudes regarding PV and ADR reporting, at baseline (Phase A) [23] and post-intervention (Phase C), were compared using a Fisher Exact test, to give an indication of statistical significance, where $p<0.05$.

\subsection{Ethical considerations}

Ethical clearance for the study was obtained from the Medunsa Research Ethics Committee (MREC/H/26/2014: PG) of the previous University of Limpopo, now known as Sefako Makgatho Health Sciences University, prior to the commencement of the study. Ethical approval was also obtained from the Gauteng Provincial Ethics Committee. Permission to conduct the study at Sebokeng Hospital was obtained from the Chief Executive Officer (CEO) of Sebokeng Hospital. All participants provided written informed consent for participation.

\section{Results}

\subsection{Background characteristics of HCPs}

Overall, 132 HCPs took part pre-intervention (Phase A) [23] and 151 post-intervention (Phase C). Characteristics of HCPs who participated in the pre-intervention and post-intervention phases are contained in Table 1.

Table 1. Background characteristics of HCPs

\begin{tabular}{|c|c|c|c|c|c|}
\hline \multirow{2}{*}{\multicolumn{2}{|c|}{ Background characteristics }} & \multicolumn{2}{|c|}{$\begin{array}{c}\text { Phase A: Pre- } \\
\text { intervention }(n=132)\end{array}$} & \multicolumn{2}{|c|}{$\begin{array}{c}\text { Phase C: Post- } \\
\text { intervention }(n=151)\end{array}$} \\
\hline & & Number & $\%$ & Number & $\%$ \\
\hline \multirow{5}{*}{ Age (years) } & $21-30$ & 39 & 29.5 & 41 & 27.2 \\
\hline & $31-40$ & 29 & 22.0 & 41 & 27.2 \\
\hline & $41-50$ & 30 & 22.7 & 40 & 26.5 \\
\hline & $51-60$ & 27 & 20.5 & 28 & 18.5 \\
\hline & $>61$ & 7 & 5.3 & 1 & 0.7 \\
\hline \multirow{2}{*}{ Gender } & Male & 30 & 22.7 & 43 & 28.5 \\
\hline & Female & 102 & 77.3 & 108 & 71.5 \\
\hline \multirow{5}{*}{$\begin{array}{l}\text { Health care } \\
\text { professional }\end{array}$} & Medical Practitioner & 31 & 24.0 & 61 & 40.4 \\
\hline & Pharmacist & 9 & 7.0 & 15 & 9.9 \\
\hline & Pharmacist Assistant & 15 & 11.0 & 22 & 14.6 \\
\hline & Nurse & 77 & 58.0 & 50 & 33.1 \\
\hline & Other & 0 & 0 & 3 & 2.0 \\
\hline
\end{tabular}

Pre-intervention: Findings from Phase A [23]; Post-intervention: Findings from Phase C

Amongst the HCPs, there were more medical practitioners (61) who completed the post-intervention questionnaire compared to the 31 in the first phase, whereas the number of nurses participating decreased from 77 to 50 .

\subsection{Training and practice on ADR reporting}

Data concerning training and practice regarding ADRs are presented in Table 2. Five (5.3\%) HCPs indicated that they had received training on ADR reporting prior to the intervention and $89.4 \%$ of HCPs indicated that they would like to receive training (Phase A). After the multiple activities (Phase B), $32.5 \%$ indicated that they have received training during the intervention, although $88.7 \%$ would 
like to receive further training. However, the number of HCPs reporting any ADR significantly increased from $12.1 \%$ to $33.8 \%$ post the interventions.

Table 2. Training and practice on ADR reporting

\begin{tabular}{|c|c|c|c|c|c|c|c|}
\hline & & \multicolumn{6}{|c|}{ Healthcare professionals; $\mathbf{n}(\%)$} \\
\hline & & $\begin{array}{c}\text { Medical } \\
\text { Practitioner }\end{array}$ & Pharmacist & $\begin{array}{c}\text { Pharmacist } \\
\text { Assistant }\end{array}$ & Nurse & Other & Total \\
\hline \multirow{2}{*}{ Sample size (n) } & Pre & 31 & 9 & 15 & 77 & 0 & 132 \\
\hline & Post & 61 & 15 & 22 & 50 & 0 & 151 \\
\hline \multirow{3}{*}{$\begin{array}{l}\text { Received training on } \\
\text { ADR reporting }\end{array}$} & Pre & 0 & $\begin{array}{c}2 \\
(22.2 \%)\end{array}$ & $\begin{array}{c}4 \\
(26.7 \%)\end{array}$ & $\begin{array}{c}1 \\
(1.3 \%)\end{array}$ & 0 & $\begin{array}{c}7 \\
(5.3 \%)\end{array}$ \\
\hline & Post & $\begin{array}{c}12 \\
(19.7 \%) \\
\end{array}$ & $\begin{array}{c}13 \\
(86.7 \%) \\
\end{array}$ & $\begin{array}{c}10 \\
(45.5 \%) \\
\end{array}$ & $\begin{array}{c}14 \\
(28.0 \%) \\
\end{array}$ & 0 & $\begin{array}{c}49 \\
(32.5 \%) \\
\end{array}$ \\
\hline & $p$ & 0.0070 & 0.0030 & 0.3136 & $<0.0001$ & $\mathrm{n} / \mathrm{a}$ & \\
\hline \multirow{3}{*}{$\begin{array}{l}\text { Would like to receive } \\
\text { training on ADR } \\
\text { reporting }\end{array}$} & Pre & $\begin{array}{c}30 \\
(96.8 \%)\end{array}$ & $\begin{array}{c}9 \\
(100 \%)\end{array}$ & $\begin{array}{c}14 \\
(93.3 \%)\end{array}$ & $\begin{array}{c}65 \\
(84.4 \%)\end{array}$ & 0 & $\begin{array}{c}118 \\
(89.4 \%)\end{array}$ \\
\hline & Post & $\begin{array}{c}54 \\
(88.5 \%)\end{array}$ & $\begin{array}{c}13 \\
(86.7 \%)\end{array}$ & $\begin{array}{c}18 \\
(81.8 \%)\end{array}$ & $\begin{array}{c}46 \\
(92.0 \%)\end{array}$ & $\begin{array}{c}3 \\
(100 \%)\end{array}$ & $\begin{array}{c}134 \\
(88.7 \%)\end{array}$ \\
\hline & $p$ & 0.2589 & 0.5109 & 0.6290 & 0.2776 & $\mathrm{n} / \mathrm{a}$ & \\
\hline \multirow{3}{*}{$\begin{array}{l}\text { Reported any } \\
\text { suspected ADR }\end{array}$} & Pre & $\begin{array}{c}4 \\
(12.9 \%)\end{array}$ & $\begin{array}{c}5 \\
(55.6 \%)\end{array}$ & 0 & $\begin{array}{c}7 \\
(9.1 \%)\end{array}$ & 0 & $\begin{array}{c}16 \\
(12.1 \%)\end{array}$ \\
\hline & Post & $\begin{array}{c}17 \\
(27.9 \%) \\
\end{array}$ & $\begin{array}{c}15 \\
(100 \%) \\
\end{array}$ & $\begin{array}{c}7 \\
(31.8 \%) \\
\end{array}$ & $\begin{array}{c}12 \\
(24 \%) \\
\end{array}$ & 0 & $\begin{array}{c}51 \\
(33.8 \%) \\
\end{array}$ \\
\hline & $p$ & 0.1230 & 0.0119 & 0.0279 & 0.0393 & $\mathrm{n} / \mathrm{a}$ & $<0.0001$ \\
\hline
\end{tabular}

Pre: Findings from Phase A [23]; Post: Findings from Phase C

\subsection{Reasons for not reporting ADRs}

Reasons given by HCPs for not reporting ADRs are presented in Figure 2. Prior to the intervention, the most prominent reasons for not reporting ADRs (54.5\%) were that they did not know how to report, where to report, and when to report ADRs. This decreased to $36.4 \%$ post-intervention $(p=0.0057)$ (Figure 2). 'Concern that the report may be wrong' decreased from $34.1 \%$ to $18.7 \%$ postintervention $(p=0.0041)$. However, there were no significant changes in a number of the other categories including 'nothing would be done with the data' and the 'medical practitioners' lack of time to look actively for ADRs' while on the ward. 
Figure 2. Reasons for not reporting ADRs

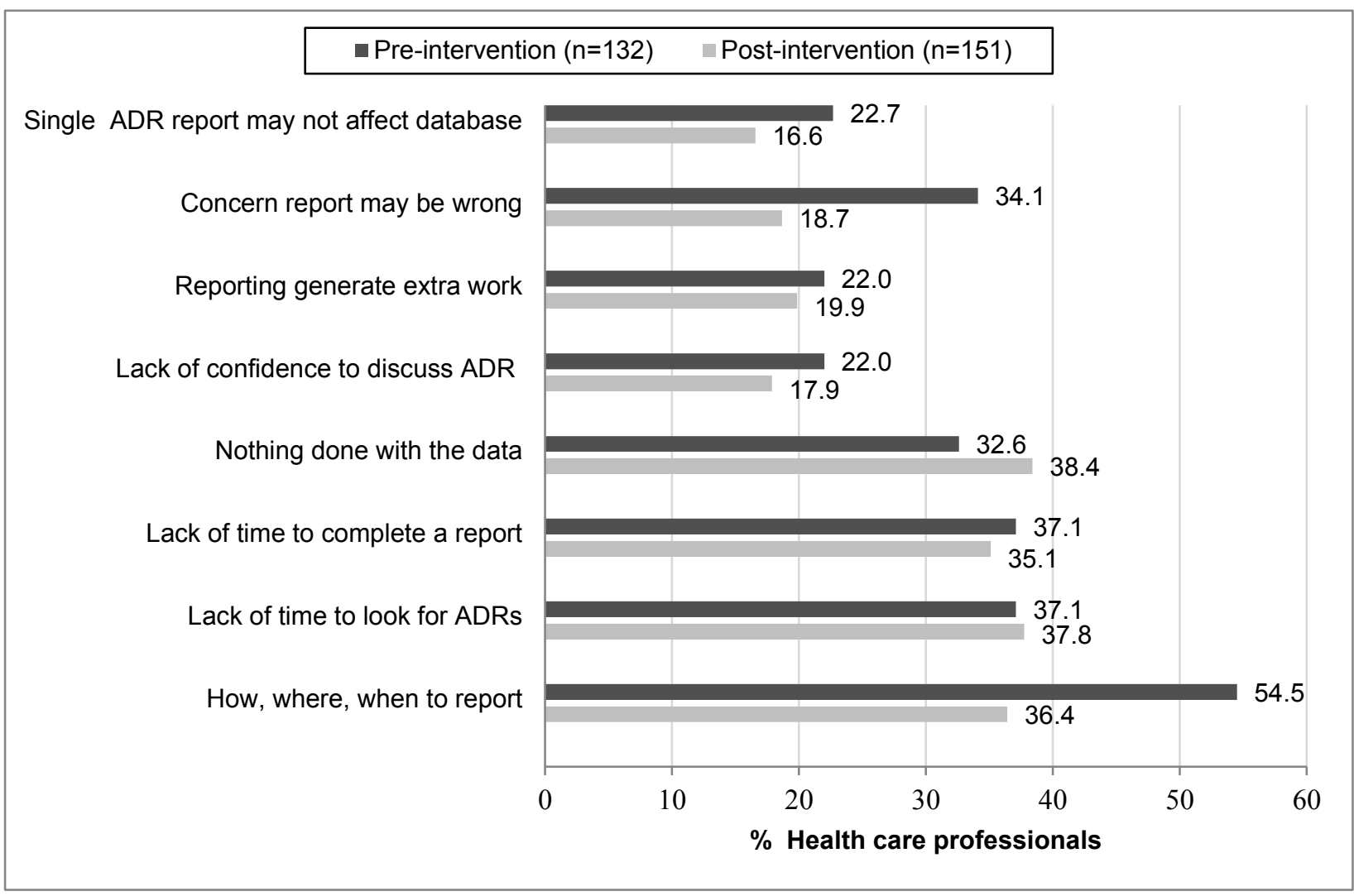

Pre-intervention: Findings from Phase A [23]; Post-intervention: Findings from Phase C

\subsection{Knowledge and attitudes regarding ADR reporting}

Table 3 presents data for changes in knowledge from baseline assessments as well as attitudes before the intervention (Phase $\mathrm{A}$ ) and after training was undertaken during the various interventions.

The interventions had a significant effect on HCPs' overall perceptions about ADR reporting. HCPs' awareness of an ADR reporting system in the hospital increased significantly following the interventions from $18.9 \%$ to $70.2 \%(p<0.0001)$. Knowledge of the availability of an ADR reporting form on the wards also increased significantly from $15.2 \%$ to $68.9 \%(p<0.0001)$. The vast majority $(98.0 \%)$ of HCPs also believed that it is necessary to report ADRs post the interventional phase $(p<0.0001)$. As a result, the reporting of ADRs appreciably increased post intervention (Table 2).

HCPs' knowledge regarding to whom the completed ADR form must be submitted also appreciably improved to $72.8 \%(p<0.0001)$. However, HCPs' perception about their professional obligation to report an ADR did not improve significantly from the high baseline of $89.4 \%$ (Table 3 ). At baseline, the majority of HCPs (82.6\%) believed that ADR reporting should be compulsory; this increased to $93.4 \%$ post-intervention. Pre-intervention (Phase A), $8.3 \%$ of HCPs felt that ADR reporting should be remunerated, while in the post-intervention questionnaire no respondents indicated that they would like to be remunerated when they reported ADRs.

HCPs' opinion about whose responsibility it is to report ADRs also changed post-intervention. The medical practitioner being responsible for ADR reporting post-intervention (87.4\%) did not change significantly from the high baseline of $85.6 \%$. However, significantly more HCPs perceived it to be also the responsibility of the pharmacist $(71.9 \%$ vs. $84.1 \% ; p=0.0142)$ and the nurse $(85.6 \%$ vs. $93.4 \% ; p=0.0479$ to report ADRs (Table 3 ). 
Table 3. Knowledge and attitudes regarding ADR reporting before and after the intervention

\begin{tabular}{|c|c|c|c|c|c|c|c|c|}
\hline & \multicolumn{6}{|c|}{ Healthcare professionals; n (\%) } \\
\hline & & & $\begin{array}{c}\text { Medical } \\
\text { Practitioner }\end{array}$ & Pharmacist & $\begin{array}{c}\text { Pharmacist } \\
\text { Assistant }\end{array}$ & Nurse & Other & Total \\
\hline \multirow{2}{*}{\multicolumn{2}{|c|}{ Sample size (n) }} & Pre & 31 & 9 & 15 & 77 & 0 & 132 \\
\hline & & Post & 61 & 15 & 22 & 50 & 3 & 151 \\
\hline \multirow{3}{*}{\multicolumn{2}{|c|}{$\begin{array}{l}\text { Aware of an } \\
\text { ADR reporting } \\
\text { system in } \\
\text { Sebokeng } \\
\text { Hospital }\end{array}$}} & Pre & $\begin{array}{c}2 \\
(6.5 \%)\end{array}$ & $\begin{array}{c}8 \\
(88.9 \%)\end{array}$ & $\begin{array}{c}5 \\
(33.3 \%)\end{array}$ & $\begin{array}{c}10 \\
(12.9 \%)\end{array}$ & 0 & $\begin{array}{c}25 \\
(18.9 \%)\end{array}$ \\
\hline & & Post & $\begin{array}{c}32 \\
(52.5 \%)\end{array}$ & $\begin{array}{c}15 \\
(100 \%)\end{array}$ & $\begin{array}{c}16 \\
(72.7 \%)\end{array}$ & $\begin{array}{c}42 \\
(84 \%)\end{array}$ & $\begin{array}{c}1 \\
(33.3 \%)\end{array}$ & $\begin{array}{c}106 \\
(70.2 \%)\end{array}$ \\
\hline & & $p$ & $<0.0001$ & 0.3750 & 0.0233 & $<0.0001$ & NA & $<0.0001$ \\
\hline \multirow{3}{*}{\multicolumn{2}{|c|}{$\begin{array}{l}\text { Know of an } \\
\text { ADR reporting } \\
\text { form available } \\
\text { in the ward or } \\
\text { hospital }\end{array}$}} & Pre & $\begin{array}{c}4 \\
(12.9 \%) \\
\end{array}$ & $\begin{array}{c}2 \\
(22.2 \%) \\
\end{array}$ & $\begin{array}{c}8 \\
(53.3 \%) \\
\end{array}$ & $\begin{array}{c}6 \\
(7.8 \%) \\
\end{array}$ & 0 & $\begin{array}{c}20 \\
(15.2 \%) \\
\end{array}$ \\
\hline & & Post & $\begin{array}{c}27 \\
(44.3 \%)\end{array}$ & $\begin{array}{c}15 \\
(100 \%)\end{array}$ & $\begin{array}{c}19 \\
(86.4 \%)\end{array}$ & $\begin{array}{c}43 \\
(86 \%)\end{array}$ & 0 & $\begin{array}{c}104 \\
(68.9 \%)\end{array}$ \\
\hline & & $\mathrm{P}$ & 0.0025 & 0.3750 & 0.0563 & $<0.00001$ & NA & $<0.0001$ \\
\hline \multirow{3}{*}{\multicolumn{2}{|c|}{$\begin{array}{l}\text { Necessary to } \\
\text { report ADRs }\end{array}$}} & Pre & $\begin{array}{c}31 \\
(100 \%) \\
\end{array}$ & $\begin{array}{c}9 \\
(100 \%)\end{array}$ & $\begin{array}{c}14 \\
(19.3 \%) \\
\end{array}$ & $\begin{array}{c}7 \\
(94.8 \%) \\
\end{array}$ & 0 & $\begin{array}{c}61 \\
(46.2 \%)\end{array}$ \\
\hline & & Post & $\begin{array}{c}60 \\
(98.4 \%)\end{array}$ & $\begin{array}{c}15 \\
(100 \%)\end{array}$ & $\begin{array}{c}20 \\
(90.9 \%)\end{array}$ & $\begin{array}{c}50 \\
(100 \%)\end{array}$ & $\begin{array}{c}3 \\
(100 \%)\end{array}$ & $\begin{array}{c}148 \\
(98.0 \%)\end{array}$ \\
\hline & & $p$ & 1.0000 & NA & 1.0000 & 0.1532 & NA & $<0.0001$ \\
\hline \multirow{3}{*}{\multicolumn{2}{|c|}{$\begin{array}{l}\text { Know to whom } \\
\text { the completed } \\
\text { ADR form must } \\
\text { be submitted }\end{array}$}} & Pre & $\begin{array}{c}4 \\
(12.9 \%)\end{array}$ & $\begin{array}{c}6 \\
(66.7 \%)\end{array}$ & $\begin{array}{c}3 \\
(20.0 \%)\end{array}$ & $\begin{array}{c}12 \\
(15.6 \%)\end{array}$ & 0 & $\begin{array}{c}25 \\
(18.9 \%)\end{array}$ \\
\hline & & Post & $\begin{array}{c}45 \\
(73.8 \%) \\
\end{array}$ & $\begin{array}{c}15 \\
(100 \%) \\
\end{array}$ & $\begin{array}{c}12 \\
(54.5 \%) \\
\end{array}$ & $\begin{array}{c}35 \\
(70.0 \%) \\
\end{array}$ & $\begin{array}{c}3 \\
(100 \%)\end{array}$ & $\begin{array}{c}110 \\
(72.8 \%) \\
\end{array}$ \\
\hline & & $p$ & $<0.0001$ & 0.0415 & 0.0471 & $<0.0001$ & NA & $<0.0001$ \\
\hline \multirow{3}{*}{\multicolumn{2}{|c|}{$\begin{array}{l}\text { ADR reporting } \\
\text { is a } \\
\text { professional } \\
\text { obligation }\end{array}$}} & Pre & $\begin{array}{c}31 \\
(100 \%)\end{array}$ & $\begin{array}{c}9 \\
(100 \%)\end{array}$ & $\begin{array}{c}11 \\
(73.7 \%) \\
\end{array}$ & $\begin{array}{c}67 \\
(87.0 \%) \\
\end{array}$ & 0 & $\begin{array}{c}118 \\
(89.4 \%)\end{array}$ \\
\hline & & Post & $\begin{array}{c}59 \\
(96.7 \%) \\
\end{array}$ & $\begin{array}{c}15 \\
(100 \%) \\
\end{array}$ & $\begin{array}{c}18 \\
(81.8 \%) \\
\end{array}$ & $\begin{array}{c}45 \\
(90.0 \%) \\
\end{array}$ & $\begin{array}{c}3 \\
(100 \%) \\
\end{array}$ & $\begin{array}{c}140 \\
(92.7 \%) \\
\end{array}$ \\
\hline & & $p$ & 0.5483 & NA & 0.6897 & 0.7803 & NA & 0.4023 \\
\hline \multirow{9}{*}{ 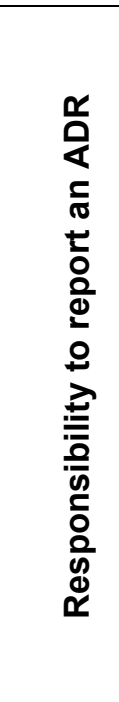 } & \multirow{3}{*}{ 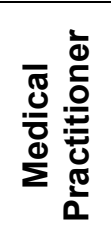 } & Pre & $\begin{array}{c}30 \\
(96.8 \%)\end{array}$ & $\begin{array}{c}9 \\
(100 \%)\end{array}$ & $\begin{array}{c}12 \\
(80 \%)\end{array}$ & $\begin{array}{c}62 \\
(80.3 \%)\end{array}$ & 0 & $\begin{array}{c}113 \\
(85.6 \%)\end{array}$ \\
\hline & & Post & $\begin{array}{c}60 \\
(98.4 \%) \\
\end{array}$ & $\begin{array}{c}15 \\
(100 \%)\end{array}$ & $\begin{array}{c}19 \\
(86.4 \%) \\
\end{array}$ & $\begin{array}{c}35 \\
(70.0 \%) \\
\end{array}$ & $\begin{array}{c}3 \\
(100 \%) \\
\end{array}$ & $\begin{array}{c}132 \\
(87.4 \%) \\
\end{array}$ \\
\hline & & $p$ & 1.0000 & NA & 0.6696 & 0.2023 & NA & 0.7278 \\
\hline & \multirow{3}{*}{$\begin{array}{l}\frac{\pi}{0.0} \\
\frac{\pi}{\pi} \\
\frac{\pi}{\pi} \\
\frac{\pi}{0}\end{array}$} & Pre & $\begin{array}{c}29 \\
(93.5 \%)\end{array}$ & $\begin{array}{c}8 \\
(88.9 \%)\end{array}$ & $\begin{array}{c}12 \\
(80.0 \%)\end{array}$ & $\begin{array}{c}46 \\
(59.7 \%)\end{array}$ & 0 & $\begin{array}{c}95 \\
(71.9 \%)\end{array}$ \\
\hline & & Post & $\begin{array}{c}54 \\
(88.5 \%)\end{array}$ & $\begin{array}{c}15 \\
(100 \%)\end{array}$ & $\begin{array}{c}21 \\
(95.5 \%)\end{array}$ & $\begin{array}{c}34 \\
(68.0 \%)\end{array}$ & $\begin{array}{c}3 \\
(100 \%)\end{array}$ & $\begin{array}{c}127 \\
(84.1 \%)\end{array}$ \\
\hline & & $p$ & 0.7127 & 0.3750 & 0.2830 & 0.4521 & NA & 0.0142 \\
\hline & \multirow{3}{*}{ 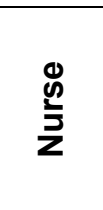 } & Pre & $\begin{array}{c}29 \\
(93.5 \%)\end{array}$ & $9(100 \%)$ & $13(86.7 \%)$ & $\begin{array}{c}62 \\
(80.5 \%)\end{array}$ & 0 & $\begin{array}{c}113 \\
(85.6 \%)\end{array}$ \\
\hline & & Post & $\begin{array}{c}57 \\
(93.4 \%) \\
\end{array}$ & $\begin{array}{c}15 \\
(100 \%)\end{array}$ & $\begin{array}{c}20 \\
(90.9 \%) \\
\end{array}$ & $\begin{array}{c}46 \\
(92.0 \%) \\
\end{array}$ & $\begin{array}{c}3 \\
(100 \%)\end{array}$ & $\begin{array}{c}141 \\
(93.4 \%) \\
\end{array}$ \\
\hline & & $p$ & 1.0000 & NA & 1.0000 & 0.1248 & NA & 0.0479 \\
\hline
\end{tabular}

Pre: Findings from Phase A [23]; Post: Findings from Phase C

\subsection{Knowledge about ADR reporting for medicines and events}

Knowledge about ADR reporting among HCPs is shown in Table 4. A significantly increased awareness was seen regarding knowledge about the reporting of ADRs from allopathic medicines, herbal medicines and blood products. The reporting of any suspected ADR, unusual event, and death due to a suspected ADR or congenital anomaly also increased significantly. 
Table 4. Knowledge of HCPs about ADR reporting for medicines and events pre- and postintervention

\begin{tabular}{|l|c|c|c|}
\hline Reasons & $\begin{array}{c}\text { Pre-intervention } \\
(\mathbf{n = 1 3 2})\end{array}$ & $\begin{array}{c}\text { Post-intervention } \\
(\mathbf{n = 1 5 1 )}\end{array}$ & $\boldsymbol{p}$ \\
\hline Categories of medicines for which ADRs should be reported \\
\hline Allopathic medicines & $78(59.1 \%)$ & $108(72.0 \%)$ & 0.0240 \\
\hline Herbal medicines & $87(66.0 \%)$ & $121(80.1 \%)$ & 0.0100 \\
\hline Blood products & $120(91.0 \%)$ & $146(96.7 \%)$ & 0.0473 \\
\hline Vaccines & $125(94.7 \%)$ & $144(95.4 \%)$ & 1.0000 \\
\hline Biological products & $112(84.1 \%)$ & $137(90.7 \%)$ & 0.1451 \\
\hline Medical devices & $111(84.1 \%)$ & $128(84.8 \%)$ & 1.0000 \\
\hline Traditional and complementary medicines & $93(70.5 \%)$ & $119(78.8 \%)$ & 0.1305 \\
\hline Events which should be reported & $121(91.7 \%)$ & $144(95.4 \%)$ & 0.2293 \\
\hline Reaction to a new drug & $120(90.9 \%)$ & $140(92.7 \%)$ & 0.6648 \\
\hline Serious event & $104(78.8 \%)$ & $139(92.1 \%)$ & 0.0019 \\
\hline Unusual event & $112(84.8 \%)$ & $131(86.8 \%$ & 0.7330 \\
\hline Well-recognized adverse reaction of a drug & $114(86.4 \%)$ & $143(94.7 \%)$ & 0.0220 \\
\hline Any suspected drug interaction & $114(86.4 \%)$ & $142(94.0 \%)$ & 0.0411 \\
\hline Death of patient due to a suspected interaction & $94(71.2 \%)$ & $128(84.8 \%)$ & 0.0061 \\
\hline Congenital anomaly & & \\
\hline
\end{tabular}

Pre: Findings from Phase A [23]; Post: Findings from Phase $\mathrm{C}$

\subsection{Experience of HCPs with the pharmacist-driven PV system}

Responses of HCPs regarding the elements of the PV system, post-intervention, are summarised in Table 5.

Table 5. Experience of HCPs with the pharmacist-driven PV system as reported postintervention

\begin{tabular}{|l|c|}
\hline \multicolumn{1}{|c|}{$\begin{array}{c}\text { Experience with the pharmacist-driven pharmacovigilance } \\
\text { system }\end{array}$} & $\begin{array}{c}\text { Health care } \\
\text { professionals ( } \mathbf{n = 1 5 1 )}\end{array}$ \\
\hline A pharmacist-driven ADR system will be supported & $145(96.0 \%)$ \\
\hline $\begin{array}{l}\text { Importance of ADR reporting is understood as a result of posters } \\
\text { and training }\end{array}$ & $128(84.8 \%)$ \\
\hline The standard operating procedure assisted in ADR reporting & $83(55.0 \%)$ \\
\hline Posters referring to ADR reporting placed in the wards were noticed & $79(52.3 \%)$ \\
\hline The box with ADR forms placed in the ward was noticed & $66(43.7 \%)$ \\
\hline Completed example ADR form displayed in the ward were used & $54(35.8 \%)$ \\
\hline Submitted an ADR report as a direct result of training received & $40(26.5 \%)$ \\
\hline ADR reports were submitted as a result of the posters & $32(21.2 \%)$ \\
\hline
\end{tabular}

\subsection{Number of ADRs reported}

In the 18 months before the intervention, a total of six ADR reports were submitted. Since the implementation of the intervention, a total of 69 ADR reports were submitted during Phase B. Forty of the 69 reported ADRs (58.0\%) were a direct result of the training, as indicted by 40 of the 151 respondents post-intervention (Table 5). However, the number of ADRs reported per HCP is unknown, hence one HCP might have reported more than one ADR. 


\section{Discussion}

We believe this is the first study in this province of South Africa to evaluate an intervention programme aimed at improving ADR reporting and HCPs' knowledge, attitudes and perceptions regarding ADRs, and also potentially within public hospitals in South Africa since the amendments to the National Health Act in 2013 [20].

The results from Phase A showed that $88 \%$ of HCPs had never reported an ADR despite the introduction of the NCS in 2011 [23], with this high rate of non-reporting similar to a tertiary centre in Nigeria (86.2\%) [24] and in India where only $22.8 \%$ of HCPs had ever reported an ADR [25]. The rate of non-reporting was significantly reduced following the interventions (Table 2), with $33.8 \%$ of HCPs indicating they had now reported an ADR. However, we believe this figure can be further increased since in a teaching referral hospital in Tehran, Iran, $84.1 \%$ of HCPs had recognised ADRs previously while $89 \%$ identified ADRs following interventions [26].

Only $19 \%$ of our respondents were aware of the existing ADR reporting system prior to the interventions, much lower than the $55.4 \%$ seen by Fadare et al. [24]. This changed following the intervention to $70.2 \%$ (Table 3), similar to the results of a study undertaken in Ghana, which found that $71.5 \%$ of the HCPs were aware of the reporting system after an intervention [27].

After the intervention, the most prominent reasons for reporting were still reactions to a new drug (95.4\%) (Table 4). However, an improvement was that HCPs would now report any suspected drug interaction $(94.7 \%)$, with a significant improvement in the likely reporting of ADRs from allopathic and herbal medicines and blood products (Table 4). Similar results were reported in a study conducted in a teaching hospital in Lagos, Nigeria, where respondents were encouraged to report ADRs if the reaction was serious $(77.8 \%)$, unusual in nature $(70.7 \%)$ and if the reaction was to a new product $(58.6 \%)[28]$.

HCPs should consider ADR reporting as an obligation [29], especially in view of their potential impact on outcomes and costs, which can be appreciably reduced with improved medicine management [35]. At Sebokeng Hospital, $98 \%$ of HCPs now indicated that it was necessary to report ADRs, similar to the findings from a tertiary hospital in India (97\%) [30]. This is encouraging.

Encouraging as well following the intervention, none of the respondents felt that ADR reporting should be remunerated, differing from Das et al. [31] where 16.7\% of doctors indicated that ADRs were not reported because of a lack of remuneration. Ray and Venugopal [30] found that $54.7 \%$ of doctors disagreed that the absence of ADR reporting was due to a lack of remuneration, although rates could be enhanced with remuneration.

Lack of knowledge of where ADRs should be reported also affects reporting rates. A study carried out by Gupta and Udopa [32] found a lack of knowledge was the main reason for under-reporting, whilst Sabblah et al. [27] reported that training significantly improved ADR reporting $(p<0.001)$. Our training and awareness programme (Phase B) appeared to contribute significantly to HCPs gaining knowledge about the ADR reporting system, among medical practitioners $(p<0.0001)$, pharmacists' assistants $(p=0.0233)$ and nurses $(p<0.0001)$ (Table 2). The lack of a significant improvement in the knowledge of pharmacists about ADRs could be due to the fact that pharmacists are more aware of and involved in ADRs of medicines (Table 2). This result is similar to a study conducted in Istanbul where the authors found that $89 \%$ of pharmacists believed that their role in ADR reporting was essential [33].

Continuous training as part of HCPs' everyday practice also increased their awareness of ADRs and improved reporting rates, with regular retraining carried out during the intervention phase (Figure 1). This indicates that regular sensitization of all HCPs on the importance of PV is effective, similar to the findings of Li et al. [34], who also showed that educational interventions improved knowledge, attitudes and the practise of reporting ADRs. In addition, similar to other studies that have shown continuous education of HCPs about PV, including ADRs, through presentations, verbal reminders, increased accessibility of report forms in wards, attendance of pharmacists in wards, and actively involving HCPs in education and training, improves their knowledge and attitudes about ADRs [27, 29, 31, 34]. 
It is well known that the beneficial effects of interventions on medical practice tend to decline over time. As a result, currently continuous discussion of ADR reporting, with subsequent reminding of HCPs to report ADRs, takes place during monthly PTC meetings in the hospital to maintain and also further improve ADR reporting at this hospital. However, we have not re-assessed the impact of this.

In order to address some of the determinants of under-reporting found in a study conducted in a tertiary centre in Northern Nigeria, it was proposed that ADR reporting guidelines should be made available in the form of booklets and posters at conspicuous locations in healthcare facilities to serve as a constant reminder [24], with educational interventions shown to improve awareness, attitudes, and practices of health-care professionals towards PV [35, 36]. In our study, $52.3 \%$ of HCPs indicated that they had noticed the posters placed in the wards regarding ADRs; however, only $21.2 \%$ indicated that the posters actually prompted them to report an ADR (Table 5). The example of a completed ADR form placed in the wards was also found useful by over a third of HCPs (35.8\%) when completing an ADR form, which is encouraging, and is being continued.

We are aware that the study was conducted in only one hospital in the Gauteng Province. Consequently, the results cannot be generalizable to all other public sector health care institutions in South Africa. We recommend a much larger study to gain a more accurate picture of current ADR reporting rates, and ways to improve them, in South Africa across all sectors. However, this initiative will take time, especially considering the challenges with operational projects. In-depth interviews could also be useful in the future to gain deeper understanding of the opinions and attitudes of the HCPs. Furthermore, although the ADR reports submitted by HCPs in this study included information necessary for causality assessment, such as the date of drug administration, date of reaction onset, outcome at de-challenge of the medication, concomitant medications and concomitant illness, the quality of the reports was not assessed. The quality of ADR reporting to enable robust causality assessment will be the focus of future studies given the positive findings with this intervention.

We are also aware that due to convenient sampling and the operational nature of the study, there are difference in the nature of HCPs taking part in both Phases (A and $\mathrm{C}$ ) with more physicians taking part in Phase C. However, the principal aim was to assess the influence of the interventions rather than match respondents between the two samples, especially given the voluntary nature of the study. Another limitation was the non-availability of pharmacists to attend ward rounds in all the wards of the hospital. Although pharmacists were allocated to the medical wards, their involvement in the ward rounds was dependent on their availability according to the time schedule of the pharmacy. This should be addressed in the future to further improve ADR reporting rates. Despite these limitations, we believe the findings are robust providing future direction to public hospitals in South Africa and wider, and our findings are already leading to changes in our hospital regarding the reporting of ADRs.

\section{Conclusion}

The study strongly indicates that the majority of HCPs did not have appropriate knowledge about the hospital's ADR monitoring and PV programme before the intervention. The implementation of an active PV system by a pharmacist proved to be successful in improving ADR monitoring and reporting in line with the goals of the National Department of Health in South Africa. ADR reporting was increased by creating awareness of an appropriate educational intervention and training on PV amongst HCPs, which should reduce future morbidity, mortality and costs among public hospital patients in South Africa. These programmes will continue in this hospital together with arguing for a greater role of hospital pharmacists to improve patient care in the future. We believe this is one of the first studies among public sector hospitals in South Africa to improve knowledge and reporting of ADRs, and the findings will be used to guide future activities among this and other public hospitals in South Africa.

\section{Acknowledgements}

Participants in the study. Pharmacy personnel from Sebokeng Hospital Pharmacy. HCPs at Sebokeng Hospital for their co-operation and willingness to participate. Sebokeng Hospital for support and allowing the study in the institution. Prof HS Schoeman is acknowledged for his assistance with the statistical analysis of the data.

Funding and conflicts of interests

There was no external funding for this research project. The authors declare no competing interest. 


\section{References}

1. Mehta UC. Pharmacovigilance: The devastating consequences of not thinking about adverse drug reactions. CME. 2011;29(6):247-251.

2. Rehan HS, Chopra D, Kakkar AK. Physician's guide to pharmacovigilance: terminology and causality assessment. Eur J Intern Med. 2009;20(1):3-8.

3. Shamim S, Sharib SM, Malhi SM, Muntaha S-u, Raza H, Ata S, et al. Adverse drug reactions (ADRs) reporting: awareness and reasons of under-reporting among health care professionals, a challenge for pharmacists. SpringerPlus. 2016;5(1):1778.

4. Mouton JP, Mehta U, Parrish AG, Wilson DPK, Stewart A, Njuguna CW, et al. Mortality from adverse drug reactions in adult medical inpatients at four hospitals in South Africa: a crosssectional survey. Br J Clin Pharmacol. 2015;80(4):818-26.5.

5. Wiktorowicz M, Lexchin J, Moscou K. Pharmacovigilance in Europe and North America: divergent approaches. Soc Sci Med. 2012;75(1):165-70.

6. Kiguba R, Karamagi C, Bird SM. Incidence, risk factors and risk prediction of hospital-acquired suspected adverse drug reactions: a prospective cohort of Ugandan inpatients. BMJ Open. 2017;7(1):e010568.

7. Maladi P. A study of adverse drug reactions reported to the adverse drug reaction monitoring centre at a tertiary care teaching hospital, Kuppam. WJPPS. 2016; 5(10):804-812.

8. Jemal A, Ward E, Hao Y, Thun M. Trends in the leading causes of death in the United States, 1970-2002. JAMA. 2005;294(10):1255-9.

9. Lazarou J, Pomeranz BH, Corey PN. Incidence of adverse drug reactions in hospitalized patients: a meta-analysis of prospective studies. JAMA. 1998;279(15):1200-5.

10. Pirmohamed M, James S, Meakin S, Green C, Scott AK, Walley TJ, et al. Adverse drug reactions as cause of admission to hospital: prospective analysis of 18820 patients. BMJ. 2004;329(7456):15-9.

11. Brvar M, Fokter N, Bunc M, Mozina M. The frequency of adverse drug reaction related admissions according to method of detection, admission urgency and medical department specialty. BMC Clin Pharmacol. 2009;9:8.

12. Tumwikirize WA, Ogwal-Okeng JW, Vernby A, Anokbonggo WW, Gustafsson LL, Lundborg SC. Adverse drug reactions in patients admitted on Internal Medicine wards in a district and Regional Hospital in Uganda. Afr Health Sci. 2011;11(1):72-8.

13. Katusiime $B$, Semakula D, Lubinga SJ. Adverse drug reaction reporting among health care workers at Mulago National Referral and Teaching hospital in Uganda. Afr Health Sci. 2015;15(4):1308-17.

14. Godman B, Finlayson AE, Cheema PK, Zebedin-Brandl E, Gutierrez-Ibarluzea I, Jones J, et al. Personalizing health care: feasibility and future implications. BMC Med. 2013;11:179.

15. Wu T-Y, Jen M-H, Bottle A, Molokhia M, Aylin P, Bell D, et al. Ten-year trends in hospital admissions for adverse drug reactions in England 1999-2009. J R Soc Med. 2010;103(6):23950 .

16. Veeren JC WM. Trends in emergency hospital admissions in England due to adverse drug reactions: 2008-2015. J Pharm Health Serv Res. 2017;8:5-11.

17. Davies EC, Green CF, Taylor S, Williamson PR, Mottram DR, Pirmohamed M. Adverse Drug Reactions in Hospital In-Patients: A Prospective Analysis of 3695 Patient- Episodes. PloS One. 2009;4(2):e4439.

18. Mehta U, Durrheim DN, Blockman M, Kredo T, Gounden R, Barnes KI. Adverse drug reactions in adult medical inpatients in a South African hospital serving a community with a high HIVIAIDS prevalence: prospective observational study. Br J Clin Pharmacol. 2008;65(3):396-406.

19. National Department of Health. National Core Standards for Health Establishments in South Africa. Republic of South Africa, Tshwane. 2011. [cited 2017 October 7] http://www.rhap.org.za/wp-content/uploads/2014/05/National-Core-Standards-2011-1.pdf.

20. Republic of South Africa. National Health Amendment Act No.12 of 2013. Government Gazette. Vol. 577. Cape Town. July 2013. No. 36702. http://www.ohsc.org.za/dev/images/NationalHealthAmendmentAct12of2013.pdf.

21. Marobobo M. Sebokeng Hospital. Monthly Statistics: Hospital Indicators. Sedibeng: Gauteng Department of Health. 2015.

22. Moeti M. Sebokeng Hospital. Monthly Statistics: Quality Assurance Adverse Events Committee Adverse Drug Reaction Reports. Sedibeng: Gauteng Department of Health. 2015. 
23. Terblanche A, Meyer JC, Godman B, Summers RS. Knowledge, attitudes and perspective on adverse drug reaction reporting in a public sector hospital in South Africa: baseline analysis. Hospital practice. 2017;45(5):238-245

24. Fadare JO, Enwere OO, Afolabi AO, Chedi BAZ, Musa A. Knowledge, attitude and practice of adverse drug reaction reporting among healthcare workers in a tertiary centre in Northern Nigeria. Trop J Pharm Res. 2011;10(3):235-242.

25. Wadagbalkar $P$, Tiwari $V$, Raipurkar $S$. Knowledge, attitudes and practice of interns regarding Pharmacovigilance in a tertiary hospital of Madhya Pradesh. JAMDSR. 2016;4(6):216-219.

26. Khaliil H, Mohebbi N, Hendoiee N, Keshtkar A, Dashti-Khavidaki S. Improvement of knowledge, attitude and perception of healthcare workers about ADR, a pre- and post-clinical pharmacists' interventional study. BMJ. 2012;2:e000367.

27. Sabblah GT, Akweongo P, Darko D, Dodoo ANO, Sulley AM. Adverse drug reaction reporting by doctors in a developing country: a case study from Ghana. Ghana Med J. 2014;48(4):189-193.

28. Oshikoya K, Awobusuyi JO. Perceptions of doctors to adverse drug reaction reporting in a teaching hospital in Lagos, Nigeria. BMC Clin Pharmacol. 2009;9:14-22.

29. Gony M, Badie K, Sommet A, Jacquot J, Baudrin D, Gauthier P, Montastruc JL, Bagheri H. Improving adverse drug reaction reporting in hospitals. Drug Saf. 2010;33(5):1-8.

30. Ray D, Venugopal A. An evaluation of knowledge, attitude and practice of pharmacovigilance among the prescribers of a medical college hospital in north eastern state of India; A cross sectional study. Indian J Pharm Pharmacol. 2015;2(4):183-190.

31. Das L, Bhattacharjee P, Ghosh R, Das UK, Ray T. Knowledge, attitude, and practice of pharmacovigilance among doctors in a tertiary care teaching hospital of Tripura. NJPPP. 2017;7(2):1-6.

32. Gupta P, Udupa A. Adverse Drug Reaction Reporting and Pharmacovigilance: Knowledge, Attitudes and Perceptions amongst Resident Doctors, Maharashtra, India. JPSR. 2011;3(2):1064-1069.

33. Toklu HZ, Uysal MK. The knowledge and attitude of the Turkish community pharmacists toward pharmacovigilance in the Kadikoy district of Istanbul. Pharm World Sci. 2008;30:556-562.

34. Li Q, Zhang SM, Chen HT, Fang SP, Yu X, Liu D, Shi LY, Zeng FD. Awareness and attitudes of healthcare professionals in Wuhan, China to the reporting of adverse drug reactions. Chin Med $J$ (Engl). 2004; 117(6):856-61.

35. Joubert MC, Naidoo P. Knowledge, perceptions and practices of pharmacovigilance amongst community and hospital pharmacists in a selected district of North West Province, South Africa. Health SA Gesondheid. 2016;21:238-44

36. Dheda M, Kambafwile H, Oosthuizen F, Bakor A, Soka A, Malangu N. A cross-sectional baseline assessment of the pharmacovigilance systems, processes and challenges faced by healthcare professionals in three south African districts prior to pharmacovigilance training and programme roll-out. PULA: Botswana Journal of African Studies. 2016;30(1). 